\title{
Electroencephalograms of Children with Permanent Cortical Visual Impairment
}

\author{
Robyn Robertson, James E. Jan and Peter K.H. Wong
}

\begin{abstract}
The electroencephalograms of 40 children with permanent cortical visual impairment (CVI) were studied. CVI was diagnosed in the presence of severe visual loss, normal or minimal ocular findings and clinical, electrodiagnostic and CT evidence of postgeniculate lesions involving the visual cortex. Al! patients had a multidisciplinary evaluation, including extensive neurological and ophthalmological investigations. The records did not contain any specific features which would be diagnostic of CVI. Isolated occipital spikes were rare and more commonly multifocal EEG disturbance was seen because of diffuse cerebral involvement. Photic stimulation was of little use in the diagnosis. Multihandicapped children with profound CVI tended to show multifocal abnormalities, no alpha rhythm and a suppressed posterior waking background in their EEGs, whereas those with more residual vision usually had an alpha rhythm. The presence or absence of alpha rhythm seemed to reflect the intactness of the striate cortex. However, the lack of alpha rhythm was not always associated with total blindness and not all children with useful residual vision had alpha thythm.
\end{abstract}

\begin{abstract}
RÉSUMÉ: Electroencéphalographie chez des enfants souffrant de déficit visuel d'origine corticale. Nous avons étudié l'électroencéphalogramme de 40 enfants souffrant de déficit visuel cortical (DVC) permanent. Le diagnostic de DVC a été posé en présence de perte de vision sévère, d'un examen oculaire normal ou ne présentant que de légères anomalies et de manifestations cliniques, électrodiagnostiques et scanographiques de lésions post-géniculée atteignant le cortex visuel. Tous les patients ont eu une évaluation multidisciplinaire, incluant une investigation neurologique et opthalmologique poussée. Les dossiers ne contenaient aucun élément spécifique permettant d'établir le diagnostic de DVC. Les perturbations électroencéphalographiques multifocales étaient plus fréquentes que les pointes occipitales isolées à cause de l'atteinte cérébrale diffuse. La stimulation lumineuse était peu utile au diagnostic. Chez les enfants souffrant de handicaps multiples avec DVC profond, l'électroencéphalogramme montrait surtout des anomalies multifocales, une absence de rythme alpha et un rythme de fond postérieur inhibé pendant l'éveil, alors que chez les enfant ayant une vision résiduelle plus importante, l'electroencéphalogramme montrait en général un rythme alpha. La présence ou l'absence de rythme alpha semblait refléter l'intégrité du cortex strié. Cependant, l'absence de rythme alpha n'était pas toujours associée à une cécité totale et tous les enfants avec une vision résiduelle utile n'avaient pas nécessairement un rythme alpha.
\end{abstract}

Can. J. Neurol. Sci. 1986: 13:256-26I

Several authors have studied the electroencephalograms (EEGs) of children blinded by various ocular disorders, most commonly retrolental fibroplasia. ${ }^{1-5}$ Total blindness due to any cause was shown to be associated with absence of alpha rhythm. Not infrequently occipital spikes were also present in the EEGs of these children, although they generally did not have epilepsy. In the largest and most comprehensive study of 192 children, Jeavons concluded that the alpha rhythm was absent in $60 \%$ of the records (Figure 1). ${ }^{4}$ The most common EEG pattern was similar to that seen in sighted subjects with their eyes open. Partially sighted children tended to have reactive alpha rhythms, but Jeavons was unable to estimate the amount of residual vision from the records alone. $38 \%$ of the EEGs showed spikes, spike and wave and sharp wave discharges maximally in the occipital areas. However, when cerebral involvement was carefully excluded only 1 child had bilateral occipital spikes.

Cortical blindness traditionally has been defined as absence of all visual sensation, normal ocular examination, loss of optokinetic nystagmus, preservation of pupillary response and normal mobility of the eyes. ${ }^{6}$ Recent studies, however, showed that this concept of cortical blindness is too restrictive. Cortical visual loss covers a spectrum ranging from no apparent vision to residual sight and not infrequently it co-exists with ocular damage due to the wide distribution of cerebral insults. ${ }^{7}$ Since 




Figure I - Posterior waking background in the EEG of a 19 year old with bilateral anophthalmia.

blindness implies total absence of vision, cortical visual loss or cortical visual impairment (CVI) is a more appropriate term.

Bergman reported that ten out of twelve patients with cortical blindness lacked alpha rhythm, but in four out of five who recovered their sight, the alpha rhythm returned. ${ }^{8}$ Jeavons noted that two out of four children with cortical blindness had alpha rhythm, but it was not reactive. ${ }^{4}$ Recently Aldrich and co-workers presented 29 adults with cortical blindness. ${ }^{9}$ They concluded that the EEG was the most useful diagnostic test, consistently demonstrating absent alpha rhythm. Unfortunately, only a brief summary of their conclusions was published. Kooi presented an adult with acquired cortical blindness whose EEG showed a normal resting background with alpha rhythm. ${ }^{10}$

The electroencephalograms of children with cortical visual loss have not been systematically studied. This may be because cortical blindness in the past was considered to be rare. In contrast to patients blinded by ocular disorders, children with cortical visual loss tend to have multiple neurological disorders such as cerebral palsy, epilepsy and mental retardation and are therefore difficult to study.

Our aim in this study was to determine the common EEG findings in children with permanent cortical visual impairment, using a less restrictive definition of $\mathrm{CVI}$ and to correlate these with clinical information and the neurological examinations.

\section{Methods}

CVI was suspected when the degree of visual loss was unexplained by the ocular examination alone. It was diagnosed in the presence of severe visual loss, normal or minimal ocular findings and clinical electrodiagnostic and $\mathrm{CT}$ evidence of postgeniculate lesions involving the visual cortex. Pure striate cortex lesions were rarely seen. Children who were not completely investigated, or had more than minimal ocular defects, were excluded. There were 40 children in the study.

These children with permanent CVI were followed by the Visually Impaired Program at the Children's Hospital. All children had a multidisciplinary evaluation, including extensive neurological and ophthalmological investigations, computed tomography (CT), visual evoked response (VER) and visual evoked potential map (VEPM) studies. The measurements of distance visual acuity by formal techniques were most often inconclusive, due to poor visual attention or lack of co-operation. Therefore acuity was graded as "no apparent vision" (0), "light perception" (1), "ability to see colourful toys measuring 5 - 6 inches within 3 feet" (2), within 10 feet (3), and over 10 feet (4). Accurate visual field testing was not possible.

The records were obtained from January, 1982 to March 1984. 47 EEGs of 40 children were analysed. The EEGs were read independently by the first two authors without prior knowledge of the clinical findings. When there was disagreement the EEGs were reviewed and a mutual concensus was decided upon.

International Ten-Twenty electrode placement was used with resistances maintained at around 3 kilo ohms. The recordings were obtained in the waking and sleep states where possible. Most children did not receive sedation but when necessary chloral hydrate was prescribed. Particular emphasis was given to obtaining passive eye closure. Photic stimulation was carried out in the waking state. The strobe ( 0.72 Joules output) was flashed at 0 - 24 flashes per second, presented as 5 seconds of light with a 5 second pause at each frequency. The EEG was taken using both bipolar and referential montages. The sensitivity was usually $7 \mathrm{uV} / \mathrm{mm}$. The time constant was routinely set at 0.3 seconds and the high frequency filter at 70 hertz. Recording times were between twenty and forty minutes.

During the last decade or so, investigators have relied heavily on the use of electroencephalographic visual evoked responses (VER) to diagnose cortical blindness. ${ }^{11.12}$ More recently, however, computer based electrodiagnostic topographic brain mapping techniques have been developed ${ }^{13}$ and as a result the response to flashes of light can now be studied simultaneously over large areas of the brain in a dynamic manner. The electrical activity is displayed as a multi-coloured, moving picture on the screen. Each state of colour within the broad spectrum corresponds to the degree of electrical activity generated in response to flash or pattern stimulation. Visual evoked potential mapping (VEPM) appears much more promising for the diagnosis of cortical visual loss than the traditional VER. ${ }^{6}$ Our patients had both VER and VEPM studies, but the analysis of this data is beyond the scope of this article.

\section{Results}

The ages of our 40 patients ranged from 6 months to 15 years. Cerebral palsy was diagnosed in 35. mental retardation in 33, epilepsy in 28 and hydrocephalus in 7 children. The age at examination, onset and degree of visual loss, aetiology, handicaps, CT findings and associated ocular findings are shown in Table I. In 15 children, minimal optic nerve abnormalities were also present, but judged insufficient to account for their blindness. They had normal pupil response to light, the minimal ocular nerve abnormality did not explain the degree of visual loss, they lacked sustained sensory nystagmus, which is the hallmark of early onset severe ocular visual loss and subsequent $\mathrm{CT}$ and electrodiagnostic investigations confirmed damage to the visual cortex.

The EEGs were analysed according to the waking background, abnormalities localised to the occipital lobe, abnormalities outside the occipital lobe and response to photic stimulation.

\section{Waking Background and the Alpha Rhythm}

The EEGs were grouped according to the presence or absence of alpha rhythm and were correlated with the clinical information and CT scans (Tables 1 and 2). 


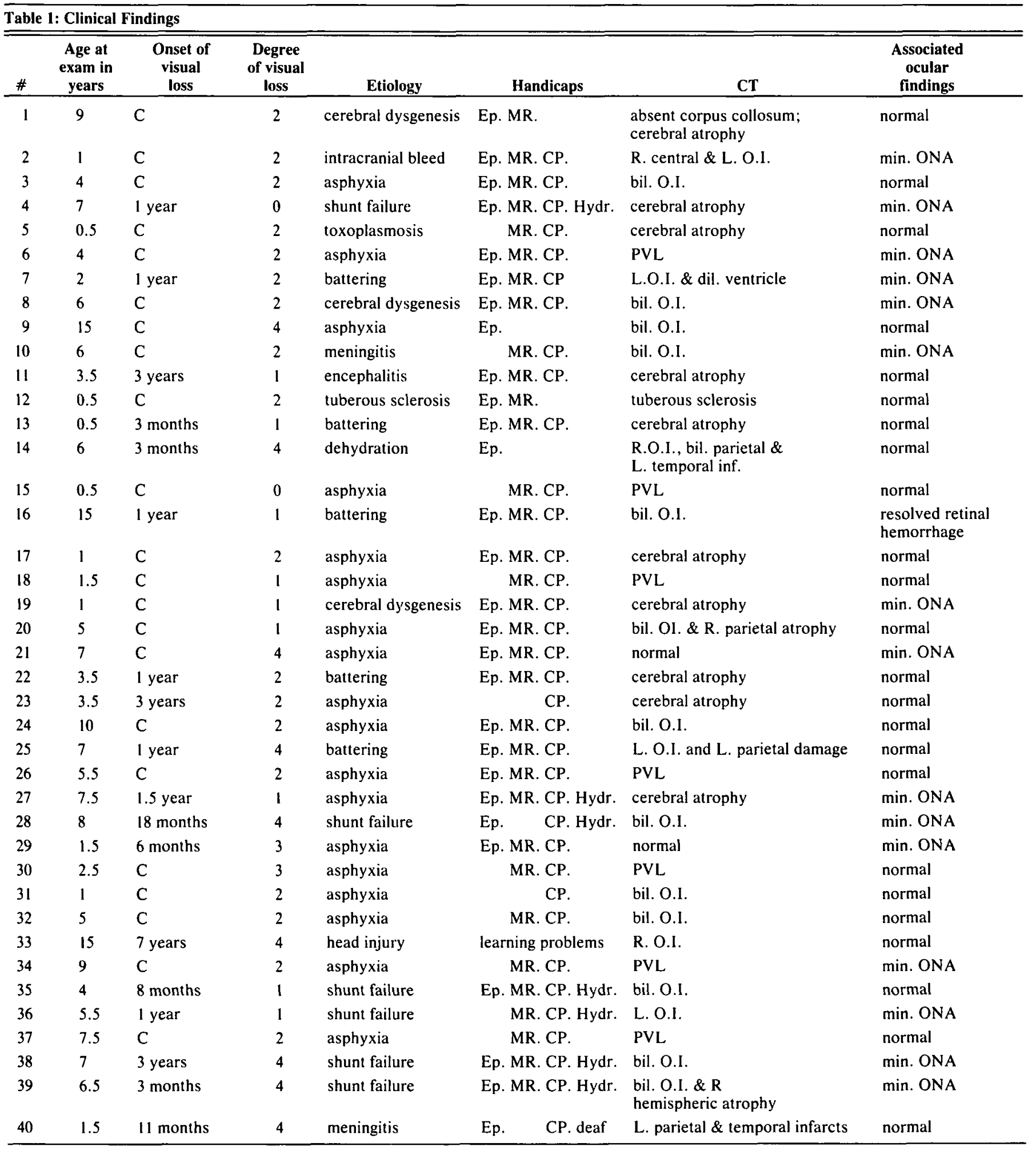

Legend:

$\begin{array}{ll}\text { C. }=\text { congenital } & \text { ONA = optic nerve atrophy } \\ \text { Ep. = epilepsy } & \text { PVL = periventricular leukomalacia } \\ \text { MR. = mental retardation } & \text { O.I. = occipital infarct } \\ \text { CP. = cerebral palsy } & \text { R. = right } \\ \text { Hydr. = hydrocephalus } & \text { L. = left } \\ & \text { bil. = bilateral }\end{array}$




\begin{tabular}{lccccc}
\hline Table 2: CT Findings in relation to alpha rhythm \\
\hline \hline $\begin{array}{c}\text { No. of } \\
\text { Patients }\end{array}$ & $\mathbf{1}$ & $\mathbf{2}$ & $\mathbf{3}$ & $\mathbf{4}$ \\
\hline CT Findings & 19 & 9 & 2 & 4 & 4 \\
\hline $\begin{array}{l}\text { Occipital infarcts } \\
\text { Cerebral atrophy }\end{array}$ & 9 & 8 & 0 & 1 & 0 \\
$\begin{array}{l}\text { Periventricular } \\
\quad \text { leukomalacia }\end{array}$ & 6 & 2 & 1 & 1 & 2 \\
$\begin{array}{l}\text { Others } \\
\text { Normal }\end{array}$ & 4 & 3 & 0 & 0 & 1 \\
\hline Total & 2 & 1 & 0 & 1 & 0 \\
\hline & 40 & 23 & 3 & 7 & 7 \\
\hline
\end{tabular}

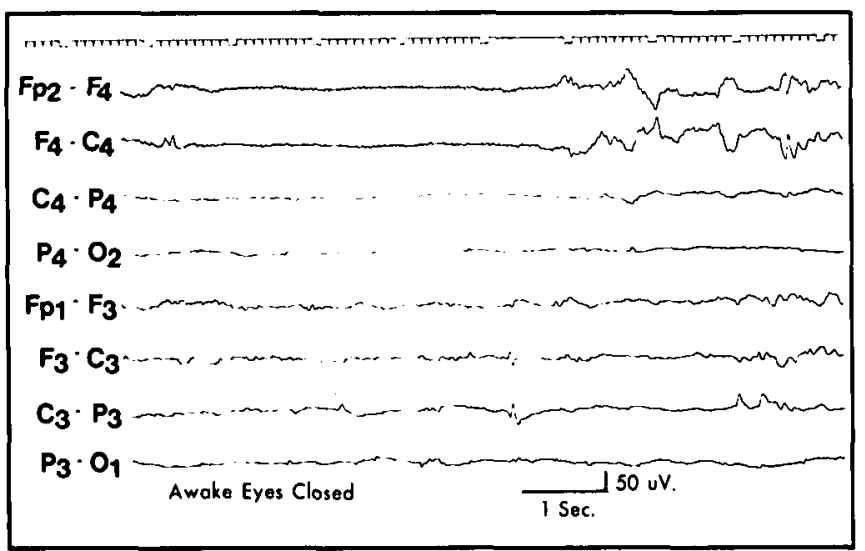

Figure 2 - Invariant low voltage posterior waking background. The child is 6 months old (No. 5).

Group 1 The posterior waking background in twenty three records (Nos. 1 - 23) revealed no alpha rhythm. Instead it consisted of invariant low voltage activity (less than $30 \mathrm{uV}$ ) or poorly defined wave forms with unmeasurable frequencies (Figure 2). Little or no changes were seen on eye closure. These patients were the most severely multihandicapped. Twenty-three children had cerebral palsy, 22 were mentally retarded and 19 had epilepsy. The vision in these patients ranged from no apparent vision (0) to the ability to see colourful toys measuring 5-6 inches within 3 feet (2) in 21 patients. Two others could see beyond 10 feet (4). Overall these patients tended to have little or no useful vision. Nine children had occipital infarctions and eight showed diffuse cerebral atrophy in their CT scans.

Group 2 In three other EEGs (Nos. 24 to 26) the posterior background frequencies were measurable, but were slow and dysrhythmic for age (Figure 3). These patients all had epilepsy, cerebral palsy and were mentally retarded. The degree of vision of these children was rated as (2) for two and (4) for one. CT scans revealed occipital infarcts in two and periventricular leukomalacia in one child.

Group 3 In a further seven EEGs (Nos. 27 to 33) the background was normal, with presence of alpha rhythm (Figure 4). Three of these children had bilateral occipital infarcts, one had unilateral occipital infarct, one demonstrated diffuse cerebral atrophy, another periventricular leukomalacia and the last patient had no abnormalities in the CT scan.

Three patients (Nos. 28, 31, 32) appeared to have tunnel vision. They all had bilateral occipital infarcts, but the CT scan showed more damage to their visual association areas than to



Figure 3 - Slow and dysthythmic posterior waking background. The child is 7 years old (No. 25 ).



Figure 4-Normal posterior waking background in the EEG of a 1.5 year old child (No. 29).

the striate cortex. Their VEPM studies also suggested relative preservation of the striate cortex (Area 17) and more damage to areas 18 and 19.

Six patients had cerebral palsy, four were mentally retarded, three had epilepsy, another three children had hydrocephalus and one experienced marked learning difficulties. Their vision ranged from light perception (1) to vision beyond ten feet (4) (Table 1). Although two of these patients saw beyond ten feet, they had severe visual perceptual difficulties, their visual acuity fluctuated, they were visually inattentive and frequently used touch to identify objects.

Group 4 The EEGs of the last seven patients (Nos. 34 - 40) showed a significant asymmetry in their alpha rhythm in either frequency or amplitude (Figure 5). These children were also multihandicapped, with variable residual vision (Tables 1 and 2).

\section{Occipital Abnormalities}

There was only a single patient (No. 33) who had bilateral independent occipital spikes and no other EEG abnormality. His CT scan showed bilateral occipital infarcts. In the records of 18 children (Nos. 2, 3, 6, 8, 9, 10, 12, 14, 15, 17, 18, 19, 21, 26, $32,35,36,39)$ there were occipital abnormalities in addition to abnormalities elsewhere. Of these 18 patients, 13 had background activity classified as Group 1, while one patient was from Group 2, another was from Group 3 and three from Group 


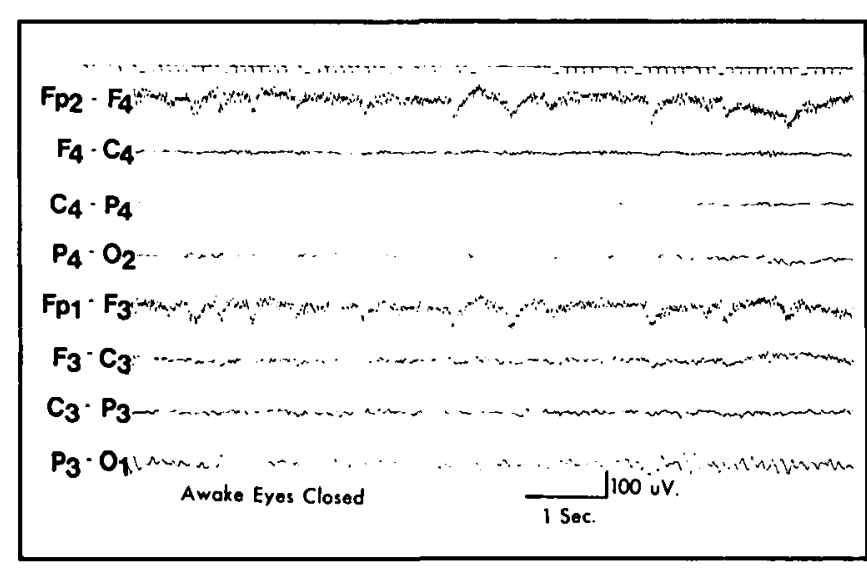

Figure 5-Asymmetric posterior waking background in a 7 year old child (No. 38).

4. Twelve of the children had multifocal findings in their EEGs while six had other focalities, which did not qualify for the multifocal definition. The abnormalities were spikes, polyspikes, delta waves, or a combination of these.

\section{Abnormalities Outside the Occipital Lobe}

Nineteen EEGs revealed multifocal spike abnormalities. Children with multifocal EEG abnormalities tended to be more severely handicapped (Table 1 shows the number of handicaps but not their severity). One child (No. 31) had no spikes in the occipital regions, but multifocal spikes elsewhere. Of the nineteen records, the background activity was classified as Group 1 in thirteen, three were in Group 2, two in Group 3 and one in Group 4. Fifteen patients had focal spikes, polyspikes or focal sharp and slow wave discharges in their EEGs. Eight of these were in Group 1. Two patients (Nos. 28 and 29) had generalised atypical spike and wave discharges. Focal delta, in addition to other abnormalities, was present in five records, but was not present alone. In two EEGs (Nos. 16 and 38) only a background abnormality was noted. For example, in record No. 16, a suppressed background was seen, without discharges. One patient (No. 27) had a normal EEG.

\section{Photic Stimulation}

Of the thirty-seven patients who had photic stimulation, only nine (24\%) showed a following response in the range of $1-24$ $\mathrm{Hz}$. Three patients (Nos. 11, 13 and 25) demonstrated well defined photic driving, although the first two children had only light perception and a low voltage, poorly defined invariant background. Two patients (Nos. 4 and 29) had minimal photic following. Four records (Nos. 14, 15, 39 and 40) showed asymmetric following response. In the last two records, the photic following occurred in the hemispheres which exhibited good background activity. None of our children had a photoconvulsive or photosensitive response.

For comparison, the last 100 consecutive normal EEGs of sighted children done at our hospital were reviewed and $70 \%$ showed a moderate or good response to photic stimulation while in $30 \%$ little or no response was seen.

\section{Discussion}

In 15 of our children, minimal optic nerve atrophy co-existed with cortical visual impairment. Since neurologically intact children with minimal ocular abnormalities have normal EEGs ${ }^{4}$ we feel that the presence of minimal optic nerve atrophy in these patients had no influence on our findings.

The majority of neurologically intact children with ocular blindness lack alpha rhythm in their EEGs. ${ }^{4}$ Similarly, in over half of the records of our patients with CVI the posterior waking background consisted of poorly defined low voltage or invariant activity without an alpha rhythm. These children generally had profound, but not necessarily total, visual loss. Those patients in our study who were able to generate alpha rhythm tended to have more residual sight. It appears therefore that lesions of the retinal-calcarine visual pathways at any site affect the generation of alpha rhythm, regardless of the aetiology. However, it is important to realise that the alpha generators may also be affected by other factors, such as an epileptogenic process. The majority of our children had epileptiform discharges in their EEGs. Furthermore, since vision is so variable in these children, the alpha generation may also be variable. While one recording may not reveal alpha, a later one might.

The EEG studies of patients with cortical visual loss are scant and disagree about the behaviour of the alpha rhythm. We believe that this can be explained. It is extremely difficult to determine that multihandicapped patients have total cortical blindness or total destruction of their striate cortex. Their visual function tends to be highly variable. At times they demonstrate no residual sight while at other times they show residual vision. CT scanning cannot confirm with absolute certainty that the visual cortex is totally destroyed. For example, two of our children with CVI had normal CT scans and others with a unilateral occipital infarct showed bilateral dysfunction of their visual cortex. It is therefore very difficult to apply the traditional definition of cortical blindness as defined by Marquis, which emphasises total loss of vision. The striate cortex receives and transmits visual information to the association areas, thus governing the ability to resolve fine detail (visual acuity) and acts as the gateway to conscious visual analysis. More complex visual interpretation occurs in the association areas. Total destruction of the striate cortex results in loss of vision. Destruction of the association areas causes visual agnosia, and these individuals see without recognition. However, in multihandicapped children it is difficult to separate profound visual agnosia from severe cortical visual loss since in both cases they appear visually impaired.

Glass has shown that when individuals with strabismic amblyopia open only their good eye, the alpha rhythm is very effectively blocked. ${ }^{14}$ By contrast, the opening of the amblyopic eye only is a poor alpha blocker. When cats or monkeys are exposed after birth to monocular deprivation, marked changes occur in the striate cortex. The great majority of monocular neurones in layer IV will switch alliance to the non-deprived eye. In humans with strabismic amblyopia a similar pathology is thought to exist. ${ }^{15}$ Therefore the striate cortex exerts a major influence on the generation of alpha rhythm. On the other hand, there is no evidence that the visual association areas or the extra-geniculocalcarine pathways influence the alpha rhythm. Indeed, three of our children had normal bilateral alpha rhythm, even though they had bilateral occipital infarcts: CT scan and VEPM studies confirmed that the striate cortex was intact, at least partially, while the association areas were severely damaged.

Isolated occipital lobe abnormalities in the EEGs of our patients were rare, but they were frequently pait of a multi- 
focal disturbance. This was because in most of our children the brain damage was diffuse. Indeed, in our series the main causes of CVI were asphyxia, shunt failure in hydrocephalic children and trauma, which can cause widespread brain damage.

Hughes et al found that $33 \%$ of a general population had no following response to photic stimulation in their EEGs. ${ }^{16}$ Similarly $30 \%$ of the last 100 consecutive normal EEGs of sighted children done at our hospital showed little or no response to photic stimulation. In contrast, photic stimulation did not produce following response in $76 \%$ of our children with CVI. The presence of photic driving indicated that the retinal-cortical pathway has not been totally destroyed, but did not correlate well with residual sight, since two of our patients with only light perception produced a following response. Thus this test is of little use in the investigation of children with CVI.

Studying children with CVI was a difficult task because they tended to be severely multihandicapped and their EEGs were markedly abnormal. The records did not contain any specific features which would be diagnostic of CVI. Nevertheless, on the basis of our experience, we feel that the EEGs of multihandicapped patients with profound CVI are likely to show a suppressed posterior waking background, no alpha rhythm and multifocal abnormalities. These EEGs are therefore different from the records of children blinded by ocular pathology, whose records are like those of sighted children with eyes open. Their alpha is absent without suppression of the background or multifocal abnormalities. Multihandicapped patients with CVI who have some useful residual vision tend to have multifocal abnormalities, and preserved alpha rhythm. Alpha rhythm is generally present in the EEGs of children with ocular disorders until the visual loss is complete or profound. Similarly the presence or absence of alpha rhythm reflects the intactness of the striate cortex. However, the lack of alpha rhythm is not always associated with total blindness and vice versa. The probable explanation is that the alpha generators are influenced not only by vision but also by other factors.

\section{REFERENCES}

1. Kellaway P, Bloxsom A, MacGregor M. Occipital spike foci associated with retrolental fibroplasia and other forms of retinal loss in children. Electroencephalogr Clin Neurophysiol 1955: 7: 469-470.

2. Cohen J, Boshes LD, Snider RS. Electroencephalographic changes following retrolental fibroplasia. Electroencephalogr Clin Neurophysiol 1961; 13: 914-922.

3. Akiyama Y, Parmelee AH, Flescher J. The electroencephalogram in visually handicapped children. J Pediatr 1964: 65: 233-242.

4. Jeavons PM. The electroencephalogram in blind children. $\mathrm{Br} \mathrm{J}$ Ophthalmol 1964; 48: 83-101.

5. Novikova LA. Blindness and electrical activity of the brain. Research Series No. 23. New York, American Foundation for the Blind 1973.

6. Marquis DG. Effects of removal of visual cortex in mammals with observations of the retention of light discrimination in dogs. Proceedings of the Association for Research in Nervous and Mental Disease 1935; 13: 558-565, Baltimore, Williams and Wilkins.

7. Whiting S, Jan JE, Wong PKH, Flodmark O, Farrell K, McCormick AQ. Permanent cortical visual impairment in children. Dev Med Child Neurol 1985; 27 : 730-739.

8. Bergman PS. Cerebral blindness. Arch Neurol 1957: 78: 568-583.

9. Alrich MS, Alessi AG, Beck RW, Gilman S. Cortical blindness in adults: etiology, diagnosis and prognosis. Ann Neurol 1984; 16: 115.

10. Kooi KA, Sharbrough FW. Electrophysiological findings in cortical blindness. Report of a case. Electroencephalogr Clin Neurophysiol 1966; 20: 260-263.

11. Barnet AB, Manson JI, Wilner E. Acute cerebral blindness in childhood. Neurology 1970; 20: 1147-1156.

12. Duchowny MS, Weiss IP. Heshmatolah M, Barnet AB. Visual evoked response in childhood cortical blindness after head trauma and meningitis. Neurology 1974: 24: 933-940.

13. Duffy FH, Burchfiel JL, Lombroso CT. Brain electrical activity mapping: a new method for extending the clinical utility of EEC and evoked potential data. Annals of Neurology 1979;5:309-321.

14. Glass JD. Alpha blocking: absence in visuobehavioral deprivation. Science 1977; 198: 58-60.

15. Wiesel TN. The postnatal development of the visual cortex and the influence of environment. Bioscience Reports 1982; 2: 351-377.

16. Hughes JR, Durtin MJ, Brown VP. Usefulness of photic stimulation in routine clinical electroencephalography. Neurology 1960: 10: 777-782. 